\title{
The Better You Feel the Better You Learn: Do Warm Colours and Rounded Shapes Enhance Learning Outcome in Multimedia Learning?
}

\author{
Hannes Müinchow, ${ }^{1}$ Christoph Mengelkamp, ${ }^{2}$ and Maria Bannert ${ }^{3}$ \\ ${ }^{1}$ Educational Psychology, University of Würzburg, Röntgenring 10, 97070 Würzburg, Germany \\ ${ }^{2}$ Media Communication, University of Würzburg, Oswald-Külpe-Weg 82, 97070 Würzburg, Germany \\ ${ }^{3}$ TUM School of Education, Technical University of Munich, Arcisstraße 21, 80335 München, Germany \\ Correspondence should be addressed to Hannes Münchow; hannes.muenchow@uni-wuerzburg.de
}

Received 8 May 2017; Accepted 2 July 2017; Published 6 August 2017

Academic Editor: Phillip J. Belfiore

Copyright ( 2017 Hannes Münchow et al. This is an open access article distributed under the Creative Commons Attribution License, which permits unrestricted use, distribution, and reproduction in any medium, provided the original work is properly cited.

\begin{abstract}
The aim of the present study was to examine whether fostering positive activating affect during multimedia learning enhances learning outcome. University students were randomly assigned to either a multimedia learning environment designed to induce positive activating affect through the use of "warm" colours and rounded shapes $(n=61)$ or an affectively neutral environment that used achromatic colours and sharp edges $(n=50)$. Participants learned about the topic of functional neuroanatomy for 20 minutes and had to answer several questions for comprehension and transfer afterwards. Affective states as well as achievement goal orientations were investigated before and after the learning phase using questionnaires. The results show that participants in the affectively positive environment were superior in comprehension as well as transfer when initial affect was strong. Preexperimental positive affect was therefore a predictor of comprehension and a moderator for transfer. Goal orientations did not influence these effects. The findings support the idea that positive affect, induced through the design of the particular multimedia learning environment, can facilitate performance if initial affective states are taken into account.
\end{abstract}

\section{Introduction}

For many years, research in multimedia learning concentrated on cognitive processes that are related to learning outcomes like the cognitive load theory (CLT) by Sweller et al. [1] or Sweller [2] and the cognitive theory of multimedia learning (CTML) proposed by Mayer [3, 4]. Nevertheless, the crucial influence of affect on learning is commonly accepted [5]. However, research on the educational effects of positive activating affect has found contradictory results. Whereas some findings indicate that positive activating affect can be beneficial for learning (e.g., [6]), there are also studies that did not find this relationship (e.g., [7],). Nevertheless, little is known about the causal influence of these affective states in short-time learning situations because most of present studies examine affect and learning in bigger spans of time (e.g., school years or semesters) or refer to correlational designs. Accordingly, research on the causal relation between positive activating affect that occurs directly while learning and learning outcome is still rare. Consequentially, it is necessary to carry out experimental studies in which affect is elicited directly in the learning situation.

In an initial work Um et al. [8] induced positive affect by using warm colours (defined here as bright and highly saturated colours of higher wavelengths) and round anthropomorphic figures as design elements in a multimedia learning environment. The results showed that inducing positive affective states increased learning outcome in terms of comprehension and transfer. Moreover, there was a positive relationship between inducing positive affect and reported levels of achievement motivation. Using the same learning environment, Plass et al. [9] partially replicated and extended these findings. Both studies therefore give initial evidence that positive activating affect can be induced directly via the design of 
the learning environment and that these affective states can foster learning outcomes. The authors refer to these findings as the so-called emotions as facilitator of learning hypothesis ([8], p. 3). Although these results are promising, subsequent research failed to coherently replicate these initial findings (e.g., $[10,11])$. Accordingly, the present study further investigates whether positive affect can be induced in the learning situation throughout the design of the learning material and whether positive affect facilitates learning outcome. Moreover, the present study considers the role of achievement goal orientations in the emotional design paradigm.

\section{Affect and Learning}

Emotions are often defined as temporary but intense affective states that are caused by internal or external stimuli [12]. Moods are often seen as unfocused, longer-lasting, and less intense states, whereas affect is generally used as an umbrella term for all emotional experiences (e.g., [13, 14]). Other authors criticize a categorical distinction and refer to a dimensional classification of emotional experiences [15]. In their view, affective states are conceptualized by different locations in the same multidimensional space. Positive activating affect includes emotions such as enjoyment or hope, whereas positive deactivating affect refers to states of relaxation or calm. Feelings of being bored or resigned are illustrative of negative deactivating affect, while emotions such as anxiety or anger exemplify negative activating affect. Moreover, it is argued that positive activation does not necessarily imply negative deactivation to the same extent and vice versa $[16,17]$. In this view, positive and negative affect are not placed on the same continuum concerning their valence, suggesting more or less separate constructs. In the present study, the term "affect" is used as an umbrella term subsuming "mood" and "emotion." Affective states are further described by levels of activation and valence.

Pekrun and colleagues [6] consider learning-related affective states as "directly linked to academic learning, classroom instruction, and achievement” (p. 92). Pekrun (e.g., [15, 18]) further emphasizes the importance of achievement emotions in the learning process. According to Pekrun [15] (p. 317), achievement emotions are defined as discrete emotions that occur in achievement situations ("activity emotions", e.g., pleasure during learning) or when a person is confronted with actual or anticipated achievement outcomes ("outcome emotions"). It is furthermore assumed that affective states (i.e., activity emotions) change dynamically while learning and directly impact learning-related cognitive and motivational processes such as self-regulation, creative problemsolving, the use of learning strategies, or intrinsic motivation [19-23]. In the present study, we investigate activity emotions, and therefore we will not elaborate any further about outcome emotions.

Empirical findings indicate that there is a broad variety of learning-related affective states that appear frequently and change dynamically in the learning situation [19]. There is some empirical evidence that induced affect is detrimental for learning outcome because of enhanced task-irrelevant thinking (e.g., [24]). Nevertheless, the results remain contradictory.
For example, Craig et al. [25] found that the affective states that occur while learning account for $27 \%$ of the variance in learning gains. Pekrun and Stephens [18] note that both positive and negative affect occur at the same frequency while learning. According to Pekrun [15] positive affect is not always beneficial and negative affect is not always detrimental for learning outcome.

It has been found that negative deactivating affect (e.g., boredom) is correlated with decreased intrinsic motivation (e.g., $[6,26])$ and negative activating affect (e.g., anger) is associated with task-irrelevant thinking [27] but may also lead to enhanced learning gains (e.g., $[28,29]$ ) and the use of more narrow, analytical, and in-depth learning strategies [30]. Positive deactivating affect such as relaxation is associated with more superficial learning strategies [31], whereas there is evidence for an increase in learning outcome when general positive activating affect is elicited [32]. Positive activating affect such as flow or enjoyment is related to better learning outcomes, broadened attention, better memory storage, and retrieval and higher levels of task persistence (e.g., $[7,20,30])$ as well as enhanced creative problem-solving and cognitive flexibility in decision making (e.g., [33-35]).

However, these findings often refer to correlational studies in which affect and trait variables like achievement motivation are analysed. Experimental studies still represent only a small proportion of the existing literature. Moreover, multimedia learning is not specifically addressed in most of these studies although multimedia learning is crucially important in educational settings [4]. In the present study, multimedia learning includes the perception and processing of information that is presented in words as well as pictures [36]. In the CTML, Mayer [4] provides a theoretical framework that describes how verbal and visual information is processed. Although several cognitive processes are described in the CTML, other important factors are not addressed. Therefore, the cognitive affective theory of learning with media (CATLM; $[37,38]$ ) expands the CTML by considering motivational and affective influences on the multimedia information processing as well (see also [39]). According to Pintrich and de Groot [40], these factors can impact learning outcome in terms of decreasing or increasing the learner's cognitive engagement. The CATLM further considers characteristics of the learner like prior knowledge and metacognitive processes that have shown to influence learning significantly (e.g., [41, 42]). Nevertheless, the theory does not provide guidelines for implementing affective interventions in concrete learning materials. Plass and Kaplan's [43] recently published integrated cognitive affective model of learning with multimedia (ICALM) addresses these issues. According to the model's main principle, cognitive and affective processes cannot be separated from each other, that is, the cognitive processing of multimedia stimuli is accompanied by affective appraisals and vice versa. Moreover, the model proposes that the instructional design of the learning material can highly influence the affective-cognitive processing. Consequently, emotional design interventions that induce learning enhancing affective states are considered to foster the affective-cognitive processing and to enhance learning outcomes. 


\section{Inducing Affective States}

Most of the most commonly used affect induction procedures present affective stimuli (e.g., pictures, film clips, or selfreferential statements) either prior to the experimental task or before every block of trials. Both approaches appear to be suboptimal for educational research studies because of several reasons. First, affective states vary in duration and intensity. Therefore, it is difficult to ensure that preexperimental induction methods are able to induce an affect that lasts for the complete learning session. It is more likely that these affective states decrease or vanish after a short amount of time, that is, within several minutes. Learning, on the other hand, often continues for longer periods. Second, affective states are reciprocally linked and can instantly influence or elicit each other [44]. According to D'Mello and Graesser [19], different affective states occur throughout learning situations. These affective experiences therefore might interfere with the preexperimental affect induction and compromise a successful emotion induction. Third, Gross [45] argues that real emotions arise in situations that are personally relevant for the individual, indicating an internal induction of affective states. Thus, affect that is elicited via the use of film clips or pictures might instead be based on compassion or empathy with the protagonists and is therefore not fully relevant to the person. To test if affect influences the learning process and the learning outcome, self-relevant positive activating affect had to be induced for the full duration of the learning situation. Alternatively, Um and colleagues [8] used highly saturated and bright colours, such as yellow or orange, and round, anthropomorphic shapes as design elements in a multimedia learning environment and were able to induce positive affective states during learning. The use of colour and form for inducing positive activating affect is therefore further discussed.

In the ecological valence theory of human colour preferences [46], it is argued that the colour of an object reveals information about its usefulness for the person and therefore causes approach or avoidance behaviour (e.g., red strawberries are preferred against green ones because the red colour signals the ripeness of the fruit). Hence, people are attracted to objects whose colours are associated with positive outcomes or advantages. These associations also appear to be highly context-specific [47]. Red, for instance, may elicit approach behaviour in the supermarket because of signalling nutritious food. In the learning context otherwise, red is more likely associated with making mistakes or failing due to the use of red ink to mark errors [48]. This is in line with the assumption that the colours wavelengths are positively correlated with increasing arousal indicating that red elicits high levels of arousal $[49,50]$. However, because of its association with making mistakes and failing in achievement situations, it is not recommended to use the colour red to induce positive affective states. Furthermore, colours do not only influence cognitive processes because of their hue but also because of their saturation and lightness [51]. Several studies by Palmer and his colleagues $[46,51]$ show that people generally prefer light and highly saturated over dark or nonsaturated colours. These colours have also been associated with positive affect in children [52] as well as college students [53]. Consequentially, bright and highly saturated colours of higher wavelengths such as orange or yellow should elicit positive activating affect.

Several studies also indicate that the shape of design elements may influence affective perceptions. Kim et al. [54], for example, found that the use of circled shapes in hypermedia environments predicts positive activating feelings such as strength and powerfulness. Other studies indicated that positive affect can be elicited by round and human-like shapes (e.g., $[10,55])$.

\section{Emotional Design in Multimedia Learning}

First evidence found that participants who learned in a multimedia learning environment which was created to elicit positive activating affect showed higher levels of learning performance than participants in an affectively neutral control condition $[8,9]$. In line with the CATLM [38], these results provide initial evidence that positive affect can be induced via the design of the learning environment and can facilitate the learning outcome. Um et al's study [8] leads to replications and extensions of the study's results. However, these studies did not develop a coherent view on the role of positive affective states while learning. While Plass and colleagues [9] reproduced the effects of the affect induction procedure at least in one out of two experiments, effects on learning performance and achievement motivation were rather heterogeneous. Contrary to Um et al. [8], they did not find learning gains for transfer in their first experiment. The second experiment showed that warm colours had no effect on the learners' positive affect, while face-like shapes did significantly foster positive affect. Hence, results on emotional design procedure were not completely coherent to the initial findings from Um and colleagues [8]. Contrarily, Park and colleagues [11] did not find that anthropomorphic design elements increase positive activating affect using the same materials as in Plass's studies. In fact, Park and colleagues [11] found an increase in positive affect for the control condition that did not receive any affect induction at all. Moreover, this study found that participants performed better when positive affect before learning was high, regardless of the emotional design of the learning environment. According to the authors, these unexpected findings were obtained because of a weak affect induction intervention and restricted variance in the reported affective states. However, these findings indicate that preexperimental affective states should be at least considered as covariates.

In two experiments, Mayer and Estrella [12] tried to replicate earlier findings. Using different materials, the authors found evidence for an emotional design procedure similar to the one introduced by Um et al. [8] enhancing learning performance. Yet, there were no differences in ratings of learning enjoyment between the treatment group and a control condition. Finally, Knörzer et al. [56] found that induced negative deactivating affects like sadness increased learning outcomes in terms of retention, comprehension, and transfer while inducing positive activating affect caused learning impairments. The authors thereby elicited positive 
activating affect using a combination of music and remembering affectively charged life events. Results concerning the relation between emotional design interventions and achievement motivation also appear disparate. Park and colleagues [11] as well as Knörzer and colleagues [56] did not find positive effects of the treatment on the participants' levels of achievement motivation. Plass et al. [9] could show that inducing positive affect also enhances intrinsic motivation at least in one of the two studies.

In sum, recent studies' findings draw a rather heterogeneous picture of the effectiveness of the induction of affect during multimedia learning on the one side and the influence of positive affect on learning outcomes on the other side. As Plass et al. [9] argued, an explanation for this result might be that learning gains in the emotional design condition may occur due to greater salience of figures that are enriched with anthropomorphic elements. Accordingly, some findings show that anthropomorphic elements are strongly connected to capturing attention [57]. Consequently, learning material that contains anthropomorphic elements may simplify the acquisition of the information not only by eliciting positive affective states but also because these figures are more conspicuous to the learner. Moreover, the implementation of human-like shapes is only possible if the shaped elements do not require a specific form by themselves. Hence, anthropomorphic shapes cannot always be implemented easily within a multimedia learning environment, especially when visualizations of the learning content do not involve figural elements (e.g., the visual representation of electrical circuits) or when these visualizations do not allow changes in shape (e.g., the visualization of anatomical structures that have predetermined shapes). In the worst case, varying the shape of such visualizations might impair learning outcomes by distorting the accuracy of the content. Therefore, a study is needed in which the learning material contains no anthropomorphic design elements but positive emotions are elicited.

\section{Research Questions and Hypotheses}

One's affective experiences while learning are supposed to be strongly connected to learning-relevant cognitive processes and have been investigated in numerous studies [18]. Positive activating affect has been found to enhance learning outcome in multimedia learning [8]. Accordingly, the present study aims to induce positive activating affect using an emotional design intervention and test its beneficial effects on the learning outcomes. In fact, it is assumed that light and saturated colours like yellow and orange and round shapes are sufficient to elicit positive activating affect. This procedure is further supposed to induce self-relevant affect because it does not refer to or focus on other human beings. Using the learning material for inducing affective states also meets the requirement that the affect will be elicited over the complete time of the learning task. Thus, it is expected that learning in an environment that elicits positive activating affect increases learning outcome compared to an environment that does not elicit such affective states. However, because of the findings from Park and colleagues [11], the present study further aims to control for any effects of preexperimental affective states as covariates. Moreover, because of strong connections between positive affect and achievement goal orientations (see [58] for a meta-analysis) it is further tested whether levels of achievement motivation may influence the effectiveness of the affect induction procedure and vice versa.

\section{Method}

6.1. Sample and Experimental Design. A total of 118 undergraduate students from a German university took part in the present study. All participants chose freely to participate in the study after being invited via e-mail. The participants selected one out of several time slots to be tested. Participants were tested in groups of up to 20 people; group size varied based on students' preference for the available time slots. Each group of participants (i.e., each time slot) was randomly assigned to one of two conditions: participants in the positive affect (PA) condition had to learn in a multimedia environment that was designed to induce positive activating affect, whereas participants in the control condition learned in an affective neutral environment. Four of the 118 participants were excluded from all analyses because they self-reported that they were highly familiar with the learning topic. Three students were excluded because they failed to give an appropriate code number to match the questionnaires from pre- to posttest. The average age of the remaining 111 participants was 20.2 years ( $\mathrm{SD}=1.8$; ranging from 18 to 27 years). Eighty-eight $(79.3 \%)$ of the students were females. Most of the participants $(100,90.1 \%)$ were studying media communication; the others were studying human computer interaction. The average study time was $2.0(\mathrm{SD}=1.0)$ semesters, meaning that most of the students were at the beginning of their studies. In sum, 61 (55\%) participants were in the PA condition, and 50 (45\%) were in the control condition. Participants were rewarded with test-taking credits.

\subsection{Materials}

6.2.1. Design of the Learning Environment. The learning material was used to manipulate affect through the use of different colours and shapes. It consisted of two hypertexts (one for each condition) on the subject of "functional neuroanatomy" written in German using HTML 5. Despite colouration and image shaping, both hypertexts were constructed identically and contained the same amount of learning content as well as the same navigation opportunities. Each hypertext contained seven sections (spinal cord, brain stem, cerebellum, mesencephalon, diencephalon, telencephalon, and prefrontal cortex), which could be navigated via the use of a navigation menu on the left side of the screen, the forward and backward buttons of the browser, or the key words of each section, which were linked with other sections. In sum, the learning material consisted of approximately 600 words. Moreover, nine figures of different parts of the human brain were used.

Figure 1 shows examples of both learning environments. The background and the images in the control condition were monochromatic; that is, we used different shades of grey. Moreover, the images in the control condition were framed with rectangular shapes. In contrast, the PA condition was 


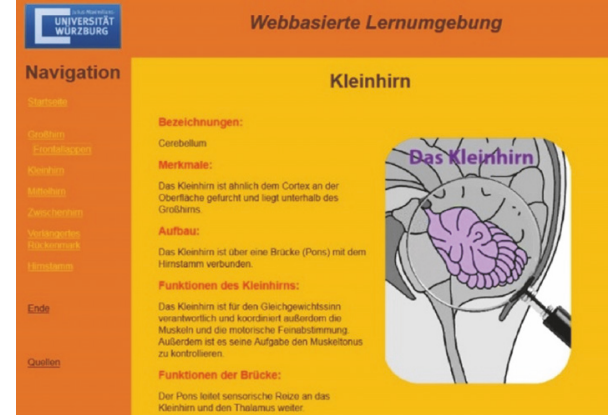

(a)

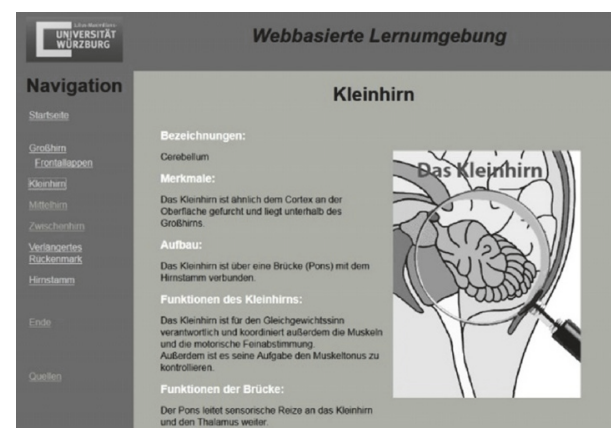

(b)

FiguRE 1: Screenshots of the two hypertext-based multimedia learning environments used in the experiment. (a) The multimedia learning environment designed to elicit positive affect by the use of bright colours and round shapes; (b) affectively neutral counterpart using achromatic colours and sharp edges.

designed using bright colours with high saturation such as yellow or orange in the background and within the images. In addition, round shapes framed all images. The images were implemented exclusively in order to induce positive activating affect in the PA condition. Therefore, they did not contain information relevant for the performance test. It was assumed that these manipulations would induce a positive activating affect during learning in the PA condition without influencing the amount or the content of the material.

\subsection{Measures}

6.3.1. Self-Assessed Prior Knowledge. Prior knowledge was assessed using the following single self-report item: "To me, the theme of 'functional neuroanatomy' is..." (a) "... completely unknown," (b) “... known, but not actively reproducible," or (c) “... completely known.” Four participants, who chose answer (b) or (c), were excluded from further analyses.

6.3.2. Activating Affect. For measuring activating affect that occurred during learning, the German version of the Positive and Negative Affect Schedule (PANAS) from Watson et al. [59] translated by Krohne et al. [60] was used. The questionnaire differs between the Positive Affect Scale (PAS) and the Negative Affect Scale (NAS), which are considered to be independent of one another [61]. According to Watson and colleagues [59], the PAS measures subjective states of feeling "enthusiastic, alert and active" (p. 1063), whereas the NAS examines the person's experience of misery and unpleasant excitement. Each scale consists of 10 items asking for the individual's experience of different emotionally charged states. In the present study, the original 5-point Likert-scale ranging from 1 = "very slightly or not at all" to 5 = "extremely" was replaced by a visual analogue scale with a range from $0=$ "not at all" to $100=$ "completely." These scales have proven to be sensitive even to small changes in affective states [62]. As mentioned by Watson and Clark [63], the PANAS is reliable, valid, and proven in measuring affect retrospectively across various studies. Moreover, the PANAS is supposed to reflect affective states on the trait as well as state level, depending on the instructions used. In the present study, a state version was used because we aimed at measuring changes in actual rather than general learning-related affect. Internal consistencies in the present study turned out quite well in pre- and postmeasures (all values for Cronbach's $\alpha$ were greater than .84).

6.3.3. Achievement Motivation. Achievement goal orientations were measured as indicators of achievement motivation. To be able to assess small changes in goal orientations, an adapted version of the SELLMO self-report questionnaire [64] was used. The original SELLMO consists of 31 items and four scales measuring mastery goal orientation, avoidance performance goal orientation, and work avoidance (8 items each) as well as approach performance goal orientation (7 items) using a 5-point Likert-scale ranging from "not at all" to "perfectly." The original item stem of the SELLMO was altered from "For me, studying is about ..." to "At the moment, I want to ..." in the present study in order to enable a more state-like measurement. Moreover, several items were changed (e.g., "... showing that I am good at something" was changed to "... showing that I am good at this task") or excluded (e.g., "... to do not have any hard exams"). Moreover, the SELLMO's work avoidance subscale was discarded. In the end, the adapted version of the SELLMO used in this study consisted of 19 items. Analogous to measuring affect, visual analogue scales ranging from $0=$ "not at all" to $100=$ "perfectly" instead of a Likert-scale were used. Internal consistencies were calculated and showed satisfactorily results with a minimum value for Cronbach's $\alpha$ of .81. This indicated that the adaption of the SELLMO to measure state instead of trait achievement motivation as well as changing the response format did not have negative consequences on the reliability.

6.3.4. Learning Outcomes. The understanding of the core content of the learning material (comprehension) and transferring the content of the learning material into new contexts ("transfer") were measured. Comprehension was assessed with 12 single choice items (with four answer options each). The items focused on asking for facts about the different parts of the human brain. To answer the questions, participants 
had to remember and integrate information derived from one or several pages in the learning material. The total number of correctly answered items was averaged and used as an index for comprehension, resulting in a score between zero, indicating that the learner had not answered any of the questions correctly, and one, indicating that the participants had answered all of the 12 questions correctly. Internal consistency was acceptable for research purposes (Cronbach's $\alpha=.61$ ) according to Nunnally and Bernstein [65]. To measure transfer participants were asked two open-ended questions. Two trained student assistants rated the answers from 0 to 3 points $(0=$ "wrong answer," $1=$ "using correct terms but incorrect relationships between them," 2 = "using correct terms and partly correct linkages between them," and 3 = "correct answer"). To succeed in answering these questions, it was necessary to integrate facts from different pages within the learning material and transfer these facts to the new problem presented in the question. The mean score across the two questions was used as an index for transfer with a minimum of 0 points, indicating wrong answers in both questions, and a maximum of 3 points, indicating totally correct answers in both questions. Cohen's kappa was calculated based on the scores of 20 randomly selected participants who were rated independently by two trained student assistants $(\kappa$ $=.81$ ). Based on the guidelines from Altmann [66], interrater reliability was substantial for the subsample.

6.4. Procedure. After being welcomed by the experimenter, participants were informed about the experiment's procedure. To mask the aim of the study, they were further told to act as beta testers for a hypertext environment. Participants then were seated in front of a computer and asked to follow the instructions presented on the screen. Before the learning phase, demographic variables, the participant's estimation of prior knowledge, and initial affect as well as achievement goal orientations were assessed. Afterwards, the participants were asked to learn for 20 minutes in either the PA or control condition ("please work with the learning material for the next 20 minutes and try to memorize as much of the presented content as possible"). During that time, all participants were free to navigate within in the learning environment. After the learning phase, learning outcome and the postexperimental affect and goal orientations were measured. Finally, the participants were thanked and informed about the real purpose of the study. In total, the experiment lasted approximately 60 minutes. All questionnaires as well as the learning test were administered with the online survey tool "SoSci Survey" [67].

\section{Results}

For hypotheses testing, differences in learning outcome were analysed between the PA and control condition. We used a regression approach for most of the analyses to include covariates as predictors in the regression and test if they are appropriate, that is, if they have the same impact on the dependent variable for both groups $[68,69]$. We graphically inspected the distribution of the studentized residuals for each regression analysis using scatterplots, histograms, and
Q-Q plots to ensure that the assumptions for regression analysis were met, and we checked for collinearity by ensuring that no tolerance was higher than .10. All of the analyses were calculated with IBM SPSS Statistics 22 software using a 5\% significance level.

7.1. Differences prior to the Learning Phase. To exclude systematic distortions due to preexperimental differences between the two conditions, a multivariate analysis of variance (MANOVA) with the preexperimental positive and negative affect as dependent variables was calculated. Descriptive statistics are shown in Table 1. Box's $M$ test indicated no violation of the equality of covariance matrices. Using Pillai's Trace, the one-way MANOVA did not show any significant differences between the control and PA condition, $V=.015$, $F(2,108)=.82, p=.451$, and $\eta_{p}{ }^{2}=.02$, which indicates that there were no systematic group differences in affect before the treatment occurred. Another MANOVA was calculated with levels of goal orientations before learning as dependent variables in order to test for differences between the two groups (see Table 1). Using Pillai's Trace, there were no significant differences between the control and PA condition, $V=.03$, $F(3,107)=1.14, p=.336$, and $\eta_{p}{ }^{2}=.03$. Hence, participants in the two conditions did not differ in levels of achievement goal orientation before the learning phase. Furthermore, the randomization for the demographic variables was checked. There were no significant differences between the conditions concerning the age of the participants, $t(109)=-.69$ and $p$ $=.490$, and the distribution of gender was the same for both conditions, $\chi^{2}(1, N=111)=.03$ and $p=.865$.

7.2. Affect before and after the Learning Phase. To check if the treatment induced positive affect we used a mixed ANOVA with pre- and postexperimental positive affect as the withinperson factor and condition as the between-person factor. Descriptive statistics can be found in Table 1. Results of the mixed ANOVA showed no significant interaction effect, $F(1$, 109) $=0.10, p=.747$, and $\eta_{p}{ }^{2}<.01$, but a significant effect of time, indicating the decrease of positive affect during the learning phase for both groups, $F(1,109)=4.41, p=.038$, and $\eta_{p}{ }^{2}=.04$. Using negative affect as the dependent variable there was neither an increase nor a decrease in negative affect during the learning phase, $F(1,109)=0.72, p=.397$, and $\eta_{p}{ }^{2}$ $=.01$, and no significant interaction of time and condition, $F(1,109)=0.30, p<.584$, and $\eta_{p}{ }^{2}<.01$.

7.3. Affect and Learning Outcome. Table 1 shows means and standard deviations for learning outcomes in terms of comprehension and transfer. We dummy-coded the conditions, using the control condition as reference group, and tested the hypothesis in three steps. First, a regression of performance on condition was calculated to test the effectivity of our treatment (hereinafter called the condition-only model). Second, potential covariates (i.e., preexperimental positive and negative affect) were added to the regression model, named the main effects model. Third, the interactions between condition and covariates were added to the model to test if the model was specified correctly, that is, if the covariates have the same effect on posttest performance for both conditions. This 
TABLE 1: Descriptive statistics of affect and performance $(N=111)$.

\begin{tabular}{|c|c|c|c|c|c|c|}
\hline & \multirow{2}{*}{$\begin{array}{l}\text { Number of } \\
\text { items }\end{array}$} & \multicolumn{2}{|c|}{ Control condition $(n=50)$} & \multicolumn{2}{|c|}{ PA condition $(n=61)$} & \multirow{2}{*}{$\begin{array}{c}\text { Internal } \\
\text { consistencies }\end{array}$} \\
\hline & & M & SD & M & SD & \\
\hline \multicolumn{7}{|l|}{ Positive affect } \\
\hline Pre & 10 & 65.38 & 9.07 & 67.39 & 9.03 & .84 \\
\hline Post & 10 & 64.20 & 9.96 & 66.26 & 11.23 & .90 \\
\hline \multicolumn{7}{|l|}{ Negative affect } \\
\hline Pre & 10 & 12.10 & 10.61 & 10.86 & 10.93 & .85 \\
\hline Post & 10 & 12.31 & 10.98 & 11.51 & 12.19 & .88 \\
\hline \multicolumn{7}{|c|}{ Mastery goal orientation } \\
\hline Pre & 7 & 50.30 & 17.37 & 55.05 & 16.69 & .82 \\
\hline Post & 7 & 48.06 & 20.23 & 49.69 & 16.82 & .87 \\
\hline \multicolumn{7}{|c|}{$\begin{array}{l}\text { Performance approach goal } \\
\text { orientation }\end{array}$} \\
\hline Pre & 5 & 45.69 & 20.67 & 50.12 & 16.81 & .81 \\
\hline Post & 5 & 42.90 & 23.72 & 47.03 & 19.02 & .86 \\
\hline \multicolumn{7}{|c|}{$\begin{array}{l}\text { Performance avoidance goal } \\
\text { orientation }\end{array}$} \\
\hline Pre & 7 & 41.48 & 23.74 & 42.12 & 22.52 & .91 \\
\hline Post & 7 & 38.24 & 26.88 & 39.98 & 24.31 & .95 \\
\hline \multicolumn{7}{|c|}{ Learning performance } \\
\hline Comprehension & 12 & .54 & .18 & .57 & .16 & .61 \\
\hline Transfer & 2 & 2.01 & .71 & 2.21 & .40 & $.81^{\mathrm{a}}$ \\
\hline
\end{tabular}

${ }^{a}$ Interrater reliability Cohen's kappa based on 20 participants selected randomly from the total sample.

model was called the interaction model. Finally, we removed all unexpected nonsignificant predictors from the model to minimize overfitting, and we ended with the final model that best explains the variance in the dependent variable.

7.3.1. Comprehension. The results from the condition-only model show that condition had no significant effect on the comprehension of the learning material, $R^{2}=.01, F(1,109)$ $=0.61$, and $p=.437$. The amount of explained variance increases significantly in the main effects model, compared to the condition-only model, $\Delta R^{2}=.11, F(2,107)=6.51$, and $p=.002$, that is, the main effects model explained $R^{2}=.11$ of variance in comprehension, $F(3,107)=4.56$ and $p=.005$. An inspection of the regression coefficients (see Table 2) shows that the more the positive affect and the less the negative affect before the learning phase are, the more the students comprehend the learning content.

The increase in predictive power over the main effects model was not significant when adding first-order interactions between condition and positive as well as negative affect, $\Delta R^{2}=.05, F(2,105)=3.01$, and $p=.053$, but nevertheless, the interaction between condition and negative affect showed a significant effect (see the interaction model in Table 2). To test for a misspecification of the model, it was also checked for the interaction between positive and negative affect and for the second-order interaction of all three main predictors, but none of these interactions became significant. The final model explained significantly more variance than the main effects model, $\Delta R^{2}=.04, F(1,106)=4.92$, and $p=.029$, and explained $R^{2}=.15$ of the variance in comprehension, $F(4,106)=4.78$ and $p<.001$. As observed from Table 2 , the condition had no significant main effect, but the main effects of positive and negative affect as well as the interaction between condition and negative affect were significant predictors of comprehension after learning.

To interpret this model, we plotted the regression lines of the interaction between comprehension and negative affect for the control and PA conditions in Figure 2. The simple slopes of comprehension on negative affect are $b=-0.081$, $t=-3.11$, and $p=.002$, for the control condition, and $b$ $=-0.004, t=-0.19$, and $p=.850$ for the PA condition. Therefore, the more the negative affect before learning is the less the students in the control condition comprehended. We calculated regions of significance for the differences between the conditions as described by Preacher et al. [70] using their website tool. For students with a centered preexperimental negative affect in the interval $[-32.5,13.6]$, the difference in comprehension between the PA and the control condition is not significant, whereas the difference is significant outside this interval. As no student in our sample had values for preexperimental negative affect below -32.5 this region is not of much interest. However, 11 students $(9.9 \%)$ have a centered negative affect higher than 13.6 before learning, and thus, for those students the PA condition led to enhanced comprehension compared to the control condition.

7.3.2. Transfer. The condition-only model showed no significant effect on transfer after the learning, $R^{2}=.03$, 
TABLE 2: Regression of performance after learning (i.e., comprehension and transfer) on condition and positive and negative affect measured before learning $(N=111)$.

\begin{tabular}{|c|c|c|c|c|c|c|}
\hline \multirow{2}{*}{ Predictors } & \multicolumn{3}{|c|}{ Comprehension } & \multicolumn{3}{|c|}{ Transfer } \\
\hline & $b$ & $t$ & $p$ & $b$ & $t$ & $p$ \\
\hline \multicolumn{7}{|l|}{ Condition only model } \\
\hline Intercept & 6.480 & 22.24 & $<.001$ & 4.020 & 25.11 & $<.001$ \\
\hline Condition & 0.307 & 0.78 & .437 & 0.390 & 1.81 & .074 \\
\hline \multicolumn{7}{|l|}{ Main effects model } \\
\hline Intercept & 6.567 & 23.55 & $<.001$ & 4.051 & 25.50 & $<.001$ \\
\hline Condition & 0.149 & 0.40 & .693 & 0.333 & 1.55 & .124 \\
\hline Positive affect & 0.035 & 2.75 & .007 & 0.009 & -1.17 & .246 \\
\hline Negative affect & -0.038 & -2.15 & .034 & -0.017 & -1.74 & .085 \\
\hline \multicolumn{7}{|l|}{ Interaction model } \\
\hline Intercept & 6.633 & 24.11 & $<.001$ & 4.040 & 25.30 & $<.001$ \\
\hline Condition & 0.129 & .35 & .729 & 0.336 & 1.56 & .121 \\
\hline Positive affect & 0.049 & 2.51 & .013 & -0.003 & -0.31 & .760 \\
\hline Negative affect & -0.078 & -2.98 & .004 & -0.019 & -1.25 & .216 \\
\hline Condition $\times$ positive affect & -0.027 & -1.05 & .297 & 0.021 & 1.38 & .169 \\
\hline Condition $\times$ negative affect & 0.074 & 2.12 & .036 & 0.001 & 0.07 & .946 \\
\hline \multicolumn{7}{|l|}{ Final model } \\
\hline Intercept & 6.619 & 24.08 & $<.001$ & 4.055 & 26.14 & $<.001$ \\
\hline Condition & 0.133 & .36 & .721 & 0.330 & 1.58 & .118 \\
\hline Positive affect & 0.034 & 2.66 & .009 & -0.012 & -1.01 & .317 \\
\hline Negative affect & -0.081 & -3.11 & .002 & -0.011 & -1.03 & .305 \\
\hline Condition $\times$ negative affect & 0.077 & 2.22 & .029 & - & - & - \\
\hline Condition $\times$ positive affect & - & - & - & 0.032 & 2.11 & .038 \\
\hline Positive $\times$ negative affect & - & - & - & 0.002 & 2.40 & .018 \\
\hline
\end{tabular}

Note. Condition was dummy-coded using the neutral affect condition as the reference group. Positive and negative affect were centered. Dashes are indicating that the predictor was not entered into the regression model.

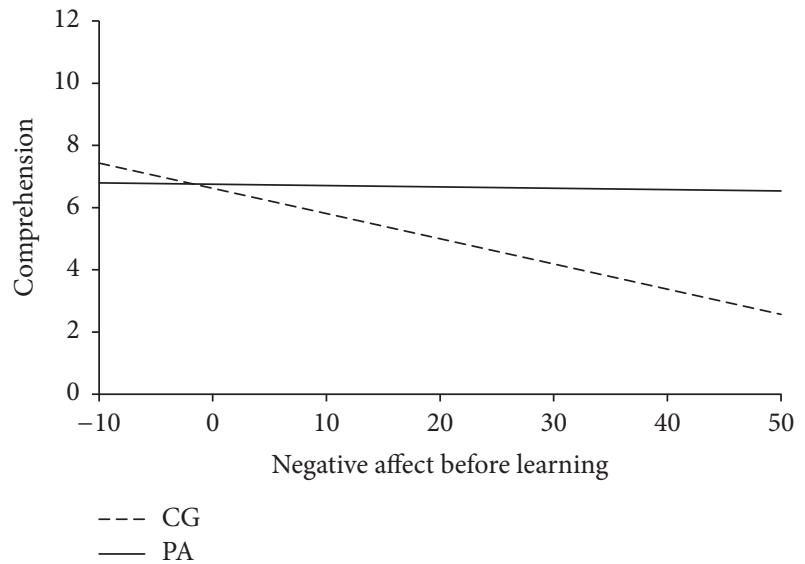

FIGURE 2: Regression of comprehension after learning on negative affect for the control group (CG) and the positive affect group (PA). Negative affect was centered; positive affect was held constantly at the average value.

$F(1,109)=3.26$, and $p=.074$ (see Table 2 ). In the main effects model the amount of explained variance did not significantly increase, $\Delta R^{2}=.04, F(2,107)=2.34$, and $p=.102$; that is, neither positive nor negative affect predicted transfer.
Similarly, the interaction model on transfer did not significantly improve the amount of explained variance compared to the main effects model, $\Delta R^{2}=.02, F(2,105)=0.96$, and $p$ $=.387$, because none of the interactions was significant (see Table 2 for regression coefficients). Finally, we tested for the interaction of negative affect before the learning phase with positive affect before the learning phase and the second-order interaction between condition, positive affect, and negative affect. This model significantly improved the amount of variance explained compared to the interaction model, $\Delta R^{2}=$ $.07, F(2,103)=4.27$, and $p=.017$. The final model explained $R^{2}=.13$ of the variance, $F(5,105)=3.24$, and $p=.009$ and will be inspected in more detail in the following.

To interpret the results, we plotted the regression lines for each condition in Figure 3. For all levels of preexperimental negative affect, there are significantly different slopes for the PA condition compared with the control condition. Thus, we will inspect this interaction only for an average level of preexperimental negative affect in more detail (see Figure 3(b)). The simple slope for the control condition was not significant, $b=-0.012, t=-1.01$, and $p=.317$, but the simple slope for the PA condition was significant, $b=$ $0.021, t=2.16$, and $p=.033$; thus, the more positive the preexperimental affect is, the more the students were able to transfer the acquired content to new problems. We calculated 


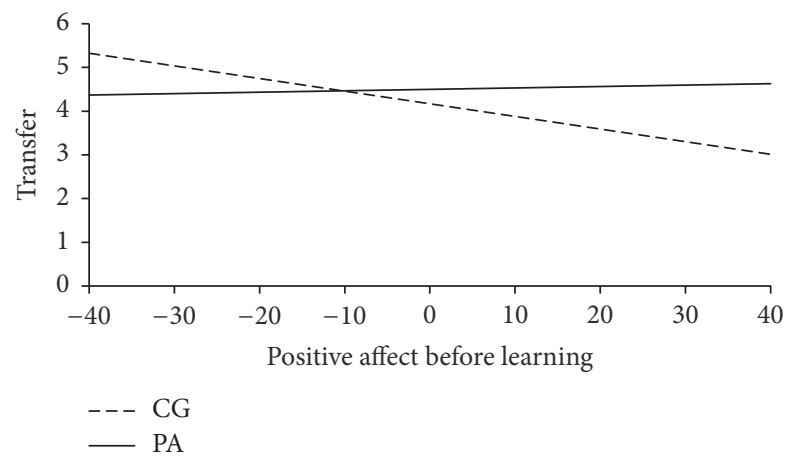

(a) Negative affect before learning 1SD below average

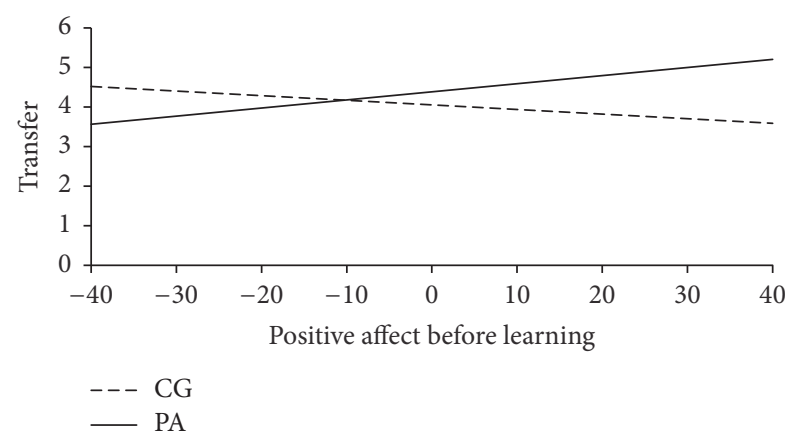

(b) Average negative affect before learning

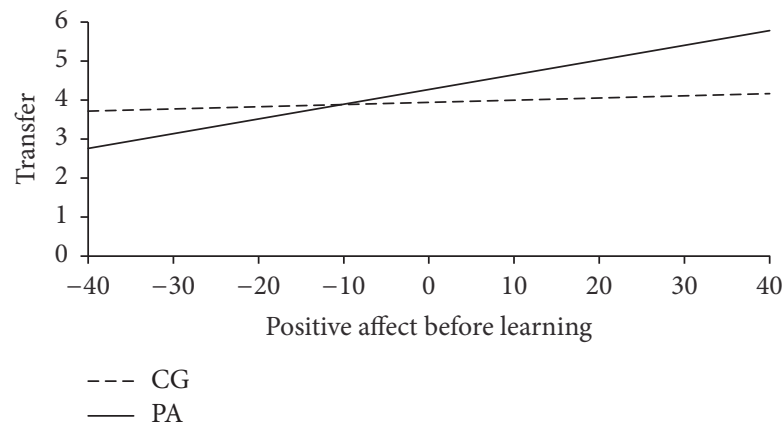

(c) Negative affect before learning 1SD above average

FIGURE 3: Regression of transfer on positive affect before learning for the positive affect group (PA) and the control group (CG) at three different levels of negative affect before learning. Positive and negative affect were centered.

the region of significance for an average preexperimental negative affect, and students from the PA condition showed lower values in transfer compared to students from the control condition within the interval of $[-\infty,-182.5$ [ for preexperimental positive affect. As no student in our sample has a preexperimental positive affect within this interval, this result is not interpreted any further. Condition does not make a difference in transfer for students with a preexperimental positive affect within the interval $[-182.5,3.0]$. There are 58 students $(52.3 \%)$ in the sample who had values within this interval. However, the PA condition was more effective than the control condition for students with a positive affect within the interval ]3.0, $+\infty$ [. As 53 students $(47.7 \%)$ in the sample have values for preexperimental positive affect within this interval, a positive effect of the PA condition on transfer can be expected for a considerable amount of the students.

This pattern of results is the same for students having a preexperimental negative affect below (see Figure 3(a)) or above average (see Figure 3(c)), but the slopes and the regions of significance for both conditions are significantly moderated by preexperimental negative affect (see the interaction of preexperimental positive affect by preexperimental negative affect in Table 3).

7.3.3. Achievement Motivation. To test for treatment effects on achievement motivation a mixed MANOVA on achievement motivation subscores (mastery, performance approach, and performance avoidance goal orientation) as dependent variables with the time of measurement (pre- versus postmeasures) as within-subject factor and type of the learning material (CG versus PA) as between-subject factor was computed. Using Pillai's Trace, there was a significant multivariate main effect of time, $V=.12, F(3,107)=5.05, p=.003$, and $\eta_{p}{ }^{2}=$ .12. Separate univariate RM-ANOVAs were significant for all achievement motivation subscores (see Table 3 ).

As can be seen in Table 1, means had decreased from preto postmeasurement in the three types of goal orientation. However, there was no significant multivariate main effect of the type of the learning environment, $V=.02, F(3,107)=.60$, $p=.615$, and $\eta_{p}{ }^{2}=.02$. Furthermore, analyses also revealed a nonsignificant interaction between the type of the learning material and the time of measurement, $V=.02, F(3,107)=$ $.81, p=.489$, and $\eta_{p}{ }^{2}=.022$. The regression coefficients for all the models are reported in Table 4 . As the only significant interaction was found for mastery goal orientation as the dependent variable, only this result will be described in more detail. In sum, the final model explained $R^{2}=.66$ of variance in the mastery goal orientation after learning, $F(4,105)=$ 50.93 and $p<.001$. Variance was explained by the mastery goal orientation before learning but also by the positive affect before learning and by the interaction of positive affect before learning and the condition. The simple slopes were $b=.30, t=2.62$, and $p=.010$ for the control condition and $b=-.06, t=-.60$, and $p=.551$ for the PA condition, indicating that positive affect before learning predicted the mastery orientation after learning for students who learned with the neutral learning environment but not for students who learned with the PA environment (see Figure 4).

Regions of significance were calculated. There were no significant differences between conditions for mastery goal orientation when the positive affect before learning was within the interval $[-43.0,5.0]$, and this was true for 69 students $(62.2 \%)$ of the sample. As no participant had a positive affect before learning that was lower than -43.0 the region below the interval is of no further interest. However, within the interval ]5.0, $+\infty$ [ for positive affect before learning, participants in the control condition reported significantly higher levels of mastery goal orientation than those in the PA condition. This was true for 42 students $(37.8 \%)$ of the sample and is contrary to what was expected in the third hypothesis. Summing up the results concerning achievement goal orientations, there was no general main effect of PA condition versus $\mathrm{CG}$ on the change of motivation during 
TABLE 3: Univariate ANOVAs of the main effect of time of measurement on achievement goal orientations before and after the learning phase $(N=111)$.

\begin{tabular}{lccc}
\hline & $F$ & $p$ & $\eta^{2}$ \\
\hline Mastery goal orientation & 12.19 & $<.001$ & .10 \\
Performance approach goal orientation & 6.21 & .014 & .05 \\
Performance avoidance goal orientation & 4.67 & .033 & .04 \\
\hline
\end{tabular}

Note. $\mathrm{df}_{\text {Model }}=1 ; \mathrm{df}_{\text {Residual }}=109$.

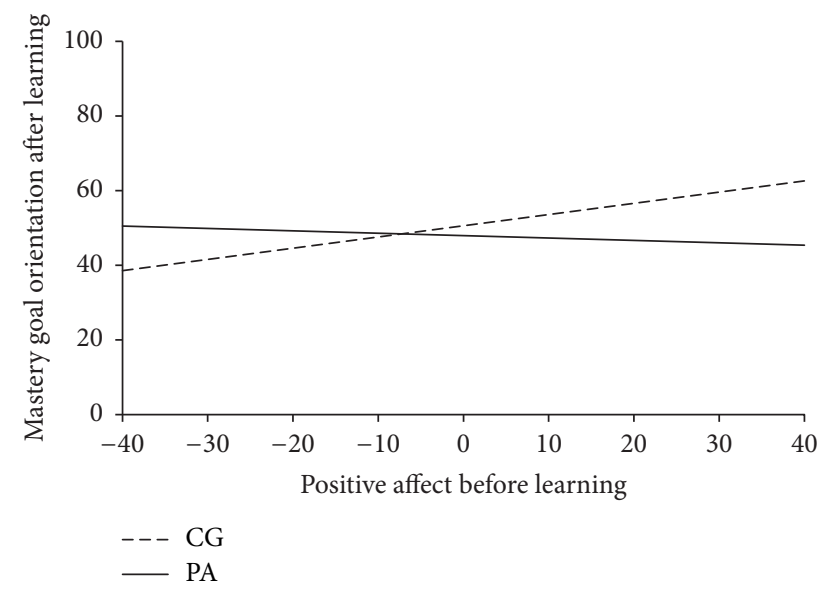

FIGURE 4: Regression of mastery goal orientation after learning on positive affect before learning for the control condition (CG) versus the positive affect (PA) condition. Positive affect before learning was centered and mastery goal orientation before learning is held constantly at the average level.

the learning. Levels of mastery goal orientation nevertheless decreased more for students in the PA condition than in the control condition given high levels of positive activating affect before learning.

\section{Discussion}

The present study examined the influence of positive affect on learning outcome during multimedia learning. We assumed that participants who learned in an environment that induced positive activating affect by using bright and highly saturated colours and rounded shapes as design features would perform significantly better in comprehension and transfer than participants who learned in an affective neutral environment. Moreover, it was checked if there were any influences of preexperimental positive and negative affect in terms of covariates and if there were any relationships between the treatment and achievement goal orientations. For performance, it was found that participants in the PA condition outperformed those in the control condition depending on initial levels of positive and negative affect. No significant influences were found concerning the role of achievement goal orientations.

\subsection{Group Differences between Positive and Neutral Condition}

8.1.1. Affect Induction. In contrast to Um et al. [8], the present study revealed no significant increase in positive activating affect. Because there were no differences in age or gender between the two conditions, the observed differences in learning outcomes nevertheless imply an effect of the independent variable at least for a subsample. Hence, it is possible that students who showed higher levels of affect before learning benefit from the treatment rather than students who did not perceive strong affects. There are several possible explanations for an only partly successful treatment. Results on the effectiveness of emotional design paradigms are generally not consistent: Um and colleagues [8] were able to induce positive affect using warm colours and anthropomorphic design elements that enhanced learning outcome; Plass and colleagues [9] only found partly similar results; Park and colleagues [11] as well as and Mayer and Estrella [10] failed in inducing positive affect.

Unlike most of the above-mentioned studies, we did not use anthropomorphic design elements in the learning materials. Besides, it was argued that baby-face-like shapes of the figures in Plass's studies could also divert attention rather than figures that did not use these shapes. Consequently, using these elements might have caused learning gains because the figures presented information that was tested after learning more saliently than those in the control condition. In contrast, the figures used in the present study provided information related to the topic but were not part of the learning test afterwards. More particularly, the figures were exclusively dedicated to enhance the efficiency of the affect induction. This ensured that performance was not increased due to better recognition or memorization of the figures. However, given the present results, it may have been the case that the treatment was not strong enough to elicit affective states. As a result, it is advised to strengthen the affect induction in future research. It is also possible that the affect induction did not persist for the whole time of learning. Maybe the affect induction had more or less quickly worn out depending on interindividual differences in affect prior to learning. Additional process measurements of affective states are recommended to check for these difficulties in future studies.

8.1.2. Learning Performance. The results on learning outcome do not generally confirm the hypotheses because differences in learning between the PA and control conditions were not significant for comprehension and only marginally significant for transfer when covariates were not considered. This contradicts previous findings [8, 9]. Nevertheless, significant interaction effects were found when covariates were taken into consideration. For comprehension, the findings indicated that high levels of negative activating affect before learning predicted a decrease of learning outcome when 


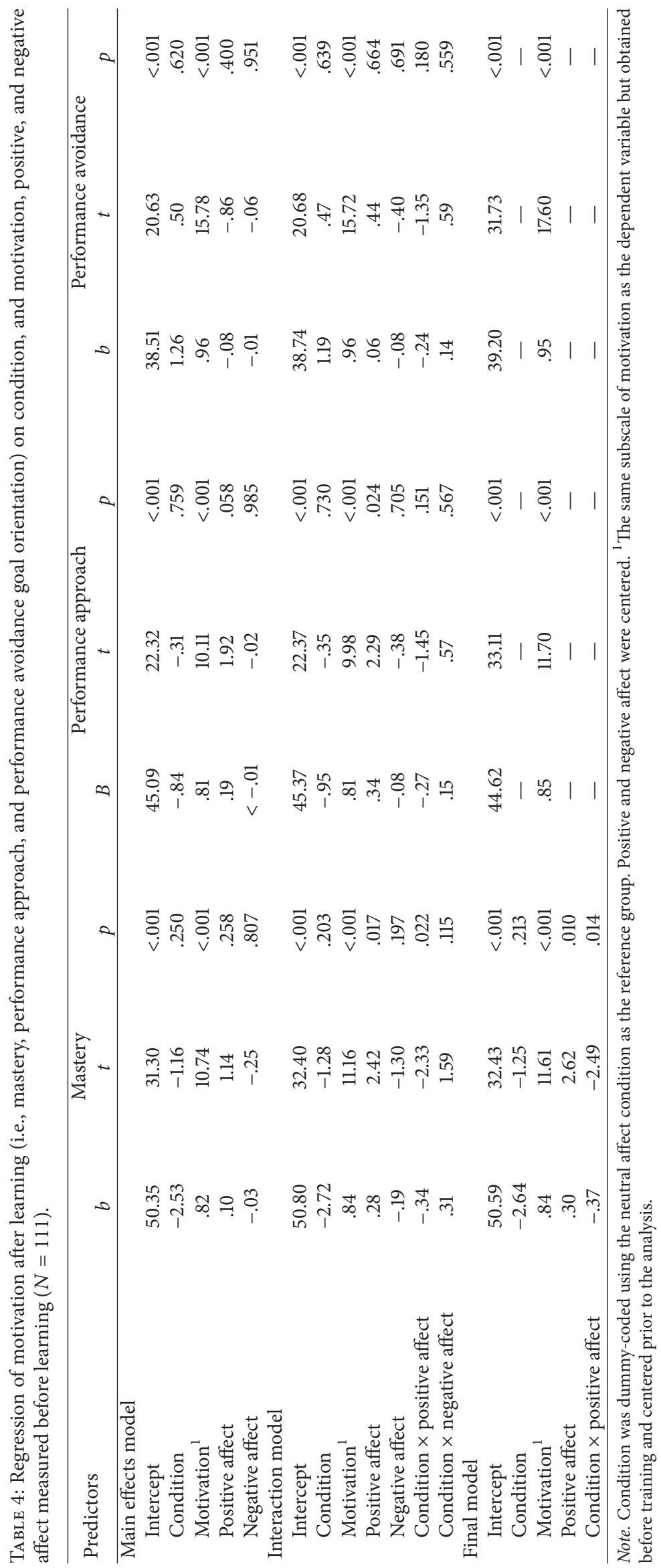


no positive affect was induced. This is in line with previous work that showed that negative activating affective states can be detrimental for learning outcomes (e.g., [26, 71]). However, participants' preexperimental negative affect did not decrease comprehension in the PA condition in which positive activating affect was induced. Therefore, the present results imply that the induction of positive activating affect may protect participants with high initial negative affect from performance deficits. Moreover, participants who experienced high levels of preexperimental positive affect performed significantly better in the transfer tasks in the PA condition compared to the control condition. In other words, participants who felt better before learning were significantly better in transferring knowledge into new contexts when they obtained the positive affect induction. This result supports earlier findings in which positive affect was associated with increased creativity and problem-solving (e.g., [30, 32]). The supremacy of the PA over the control condition in transfer was further found for all levels of preexperimental negative affect. These results contradict findings of Um et al. [9] who did not only induce positive affect while learning via the design of the learning material but also beforehand by using an imaginative and self-referencing induction method. Participants that received a positive affect induction and had to learn in the positive affect condition nevertheless did not outperform other participants. However, using the same materials as Um et al. [8], Park et al. [11] found very similar results to those that were found in our study; that is, inducing positive affect through colour and shape can enhance transfer outcomes at least if positive affect before learning is high. Consequently, the present results contradict findings that have concluded a detrimental effect of positive activating affective states [56]. Hence, in this experimental study, affective states before learning also predicted the success of an emotional design paradigm in order to enhance learning performance.

8.1.3. Achievement Motivation. There were no differences between the positive affect and control condition in the change of the goal orientations. These findings differed from the results of Um et al. [8] and, for example, Linnenbrink [7] who found an increase of intrinsic and extrinsic motivation when inducing positive affect. Aspinwall [31] argued that positive affective states may reduce motivation to learn because the motivation of doing something (e.g., learning) that is likely to disrupt a current state of pleasantness should be rather low. Accordingly, our results revealed a significant interaction; that is, students with high levels of positive affect before learning reported higher levels of mastery goals in the control condition than in the PA condition. Therefore, inducing positive activating affect may cause decreases in mastery goals when participants are highly positively activated because they do not want this state being disrupted.

However, our results are different to previous studies (e.g., $[8,72])$ and a meta-analysis by Huang [58] reporting positive correlations between positive affect and mastery goals. Nevertheless, Brown [73] also found a negative relation. The obtained results can be interpreted at least in two ways: first, there was no increase in levels of mastery goal orientation because, contrary to trait goal orientations, positive affect and state goals might not be positively correlated. Second, the results indicate that a relatively small intervention (variation of the colours and shapes of the learning material) cannot significantly alter deeply entrenched constructs like goal orientations so easily. The first explanation seems rather unlikely because it is assumed that the changes that were made to measure state level did not alter the items drastically; that is, the adaptions should not have resulted in constructing completely unrelated constructs compared to the original scale. Additionally, trait achievement goal orientations describe an individual's tendency to try to achieve certain goals in various achievement situations. State achievement goals on the other hand may be linked more closely to the actual setting and can vary to some degree across different achievement situations, e.g., depending on experienced levels of control over the situation and the subjective value of reaching that specific goal [15]. Thus, trait and state levels should nevertheless be correlated substantially. Furthermore, there are findings that show that positive activating affect is associated with higher pursuit to accomplish one's goals in academic settings [74]. Albeit goal orientations can be altered experimentally (e.g., $[75,76]$ ), it is still more suitable to assume that goal orientations do not vary strongly by a slight intervention as realized in this experiment.

8.2. Limitations and Future Work. There are several constraints concerning our study. First, the assessment of positive and negative affect might be compromised in several ways due to single-source biases. In his component process model, Scherer (e.g., $[12,77]$ ) defines affective states as different patterns of appraisals regarding affective, cognitive, motivational, peripheral physiological, and expressive components of emotional experiences. Self-assessment questionnaires do not address all of these components and therefore may not be sufficient for measuring affective experiences exhaustively. Hence, difficulties in using self-reports cannot be excluded; that is, participants might have answered our questionnaires, for example, based on social desirability. Moreover, retrospective assessment of affective states might be confounded by memory distortions. Affect further changes dynamically [19] during learning. These changes cannot be observed using questionnaires after the learning situation. Future research should consider these limitations by using multiple methods for assessing affective states, such as physiological data as well as video recordings of the learning situation.

Moreover, although there is evidence that bright and saturated colours as well as round shapes are associated with positive activating affect (e.g., [52, 54]), Elliot and Maier [47] state that empirical findings are not consistent in this field of research. The authors particularly doubt that colours with longer wavelengths elicit physiological arousal. Consequentially, more studies have to be performed in which the colouring scheme is varied. Additionally, our induction method is similar but not equivalent to the one that was used by Um et al. [8] and Plass et al. [9]; that is, we did not use anthropomorphic figures. Yet, it is an open question whether the two induction methods differ in eliciting affective states. Moreover, due to insignificant differences in pre- and postaffect it might also be assumed 
that the omission of anthropomorphic forms may create an affect induction that is too subtle for eliciting affective states that are perceived and expressed consciously by the learners. Furthermore, our study only considers interaction effects between affective states before learning and emotional design procedures intended to elicit positive activating affect. However, specific colours and shapes could also elicit negative affective states (e.g., the use of the colour red, which might be associated with academic failure) that may impair learning outcomes. To date, not much is known about the interaction between induced negative affect and the learners' affective states before learning. This seems to be due to findings from correlational studies (see, e.g., [18] for a review) that negative affect (e.g., test anxiety) often is not beneficial for learning.

Nevertheless, our results on learning outcome form a consistent picture: inducing positive affect predicted better comprehension and transfer for participants with high levels of initial positive or negative affect. However, although our treatment seemingly worked for at least some of the participants, we do not know the mechanisms underlying these effects. In fact, the influence of negative activating affect before learning on our treatment cannot presently be explained because our affect induction was meant to induce positive affect and not to reduce negative affect. Additionally, further studies should assess prior knowledge with a performance test instead of using self-reports.

To sum up, the present study provides additional evidence for positive emotions potential to facilitate outcomes in multimedia learning. From an instructional point of view, the understanding of the mechanisms that elicit positive affect during learning is useful for improving outcomes and should thus be investigated in future research. Our study revealed complex patterns of interactions between the induction of affective states and preexperimental positive and negative affect in a short-time learning situation. If these patterns remain stable in future research, such treatments will require taking initial affective states of the learner seriously into consideration. However, treatments for fostering learning outcomes have to be applicable in real classrooms. It would do no harm if teachers strengthen their students' positive affects (e.g., by using learning materials that contain emotional design principles). At best, students who are at least in a nonneutral affective state before learning will do better in terms of comprehending learning contents and transferring this information into new contexts. Somewhat challenging in classroom contexts is the adoption of the emotional design to the current affective status of each single student; this may only be an option in intelligent, personalized learning systems (e.g., intelligent tutoring systems [78]).

\section{Disclosure}

An earlier version of this work has been presented at EARLI conference 2015.

\section{Conflicts of Interest}

The authors declare that there are no conflicts of interest regarding the publication of this paper.

\section{Acknowledgments}

This publication was funded by the German Research Foundation (DFG) and the University of Würzburg in the funding programme Open Access Publishing.

\section{References}

[1] J. Sweller, J. J. G. van Merrienboer, and F. Paas, "Cognitive architecture and instructional design," Educational Psychology Review, vol. 10, no. 3, pp. 251-296, 1998.

[2] J. Sweller, "Implications of cognitive load theory for multimedia learning," in The Cambridge Handbook of Multimedia Learning, R. E. Mayer, Ed., 30, p. 19, Cambridge University Press, Cambridge, UK, 2005.

[3] R. E. Mayer, "Cognitive theory of multimedia learning," in The Cambridge Handbook of Multimedia Learning, R. E. Mayer, Ed., pp. 31-48, Cambridge University Press, New York, NY, USA, 2005.

[4] R. E. Mayer, Multimedia Learning, Cambridge University Press, New York, NY, USA, 2nd edition, 2009.

[5] C. Kim and R. Pekrun, "Emotions and motivation in learning and performance," in Handbook of research on educational communications and technology, J. Spector, M. Merrill, J. Elen, and M. Bishop, Eds., pp. 65-75, Springer, New York, NY, USA, 2014.

[6] R. Pekrun, T. G, W. Titz, R. P. Perry, and T. Götz, "Academic emotions in students self-regulated learning and achievement: a program of qualitative and quantitative research," Educational Psychologist, vol. 37, no. 2, pp. 91-106, 2002.

[7] E. A. Linnenbrink, "The role of affect in student learning: a multi-dimensional approach to considering the interaction of affect, motivation, and engagement," in Emotion in Education, P. a. Schutz and R. Pekrun, Eds., pp. 107-124, Academic Press, San Diego, Calif, USA, 2007.

[8] E. Um, J. L. Plass, E. O. Hayward, and B. D. Homer, "Emotional design in multimedia learning," Journal of Educational Psychology, vol. 104, no. 2, pp. 485-498, 2012.

[9] J. L. Plass, S. Heidig, E. O. Hayward, B. D. Homer, and E. Um, "Emotional design in multimedia learning: effects of shape and color on affect and learning," Learning and Instruction, vol. 29, pp. 128-140, 2014.

[10] R. E. Mayer and G. Estrella, "Benefits of emotional design in multimedia instruction," Learning and Instruction, vol. 33, pp. 12-18, 2014.

[11] B. Park, J. L. Plass, L. Knörzer, and R. Brünken, "Emotional design and positive emotions in multimedia learning: an eyetracking study on the use of anthropomorphisms," Computers Education, vol. 86, pp. 30-42, 2015.

[12] V. Shuman and K. R. Scherer, "Concepts and structures of emotions," in International Handbook of Emotions in Education, R. Pekrun and L. Linnenbrink-Garcia, Eds., pp. 13-35, Routledge, New York, NY, USA.

[13] A. Efklides and C. Petkaki, "Effects of mood on students metacognitive experiences," Learning and Instruction, vol. 15, no. 5, pp. 415-431, 2005.

[14] D. B. McLeod and V. M. Adams, Affect and Mathematical Problem Solving - A New Perspective, Springer, New York, NY, USA, 1989.

[15] R. Pekrun, “The control-value theory of achievement emotions: assumptions, corollaries, and implications for educational research and practice," Educational Psychology Review, vol. 18, no. 4, pp. 315-341, 2006. 
[16] A. Tellegen, D. Watson, and L. A. Clark, "On the dimensional and hierarchical structure of affect," Psychological Science, vol. 10, no. 4, pp. 297-303, 1999.

[17] D. Watson and A. Tellegen, "Toward a consensual structure of mood," Psychological Bulletin, vol. 98, no. 2, pp. 219-235, 1985.

[18] R. Pekrun and E. J. Stephens, "Academic emotions," in APA educational psychology handbook, K. R. Harris, S. Graham, and T. C. Urdan, Eds., vol. 2, pp. 3-31, American Psychological Association, Washington, D.C, USA, 2011.

[19] S. K. D'Mello and A. C. Graesser, "Dynamics of affective states during complex learning," Learning and Instruction, vol. 22, no. 2, pp. 145-157, 2012.

[20] A. Efklides, A. Kourkoulou, F. Mitsiou, and D. Ziliaskopoulou, "Metacognitive knowledge of effort, personality factors, and mood state: their relationships with effort-related metacognitive experiences," Metacognition and Learning, vol. 1, no. 1, pp. 33-49, 2006.

[21] A. Erez and A. M. Isen, "The influence of positive affect on the components of expectancy motivation," The Journal of Applied Psychology, vol. 87, no. 6, pp. 1055-1067, 2002.

[22] E. A. Linnenbrink and P. R. Pintrich, "Achievement goal theory and affect: an asymmetrical bidirectional model," Educational Psychologist, vol. 37, no. 2, Article ID S15326985, pp. 69-78, 2002.

[23] E. A. Linnenbrink and P. R. Pintrich, "The role of motivational beliefs in conceptual change," in Reconsidering Conceptual Change: Issues in Theory and Practice, M. Limon and L. Mason, Eds., pp. 115-135, Kluwer Academic Publishers, Dordrecht, Dordrecht, 2002.

[24] H. C. Ellis, R. L. Thomas, and I. A. Rodriguez, "Emotional mood states and memory: elaborative encoding, semantic processing, and cognitive effort," Journal of Experimental Psychology. Learning, Memory, and Cognition, vol. 10, no. 3, pp. 470-482, 1984.

[25] S. D. Craig, A. C. Graesser, J. Sullins, and B. Gholson, "Affect and learning: an exploratory look into the role of affect in learning with AutoTutor," Journal of Educational Media, vol. 29, no. 3, pp. 241-250, 2004.

[26] R. Pekrun, T. Götz, L. M. Daniels, R. H. Stupnisky, and R. P. Perry, "Boredom in achievement settings: exploring controlvalue antecedents and performance outcomes of a neglected emotion," Journal of Educational Psychology, vol. 102, no. 3, pp. 531-549, 2010.

[27] R. Pekrun, T. Götz, R. P. Perry, K. Kramer, M. Hochstadt, and S. Molfenter, "Beyond test anxiety: development and validation of the test emotions questionnaire (TEQ)," Anxiety, Stress \& Coping, vol. 17, no. 3, pp. 287-316, 2004.

[28] S. K. D’Mello and A. C. Graesser, "Confusion," in International Handbook of Emotions in Education, R. Pekrun and L. Linnenbrink-Garcia, Eds., pp. 289-310, Routledge, New York, NY, USA, 2014.

[29] S. K. D’Mello, B. Lehman, R. Pekrun, and A. C. Graesser, “Confusion can be beneficial für learning," Learning and Instruction, vol. 29, pp. 153-170, 2014.

[30] B. L. Fredrickson, "The role of positive emotions in positive psychology: the broaden-and-build theory of positive emotions," American Psychologist, vol. 56, no. 3, pp. 218-226, 2001.

[31] L. G. Aspinwall, "Rethinking the role of positive affect in selfregulation," Motivation and Emotion, vol. 22, no. 1, pp. 1-32, 1998.

[32] R. T. Nadler, R. Rabi, and J. P. Minda, "Better mood and better performance: Learning rule-described categories is enhanced by positive mood," Psychological Science, vol. 21, no. 12, pp. 17701776, 2010.
[33] A. M. Isen, "Some perspectives on positive affect and self-regulation," Psychological Inquiry, vol. 11, no. 3, Article ID S15327965, pp. 184-187, 2000.

[34] A. M. Isen, K. A. Daubman, and G. P. Nowicki, "Positive affect facilitates creative problem solving," Journal of Personality and Social Psychology, vol. 52, no. 6, pp. 1122-1131, 1987.

[35] A. M. Isen, A. S. Rosenzweig, and M. J. Young, "The influence of positive affect on clinical problem solving," Medical Decision Making, vol. 11, pp. 221-227, 1991.

[36] R. E. Mayer and R. Moreno, "Nine ways to reduce cognitive load in multimedia learning," Journal of Educational Psychology, vol. 38, no. 1, pp. 43-52, 2003.

[37] R. Moreno, "Instructional technology - Promise and pitfalls," in Technology-based education: Bringing researchers and practitioners together, L. PytlikZillig, M. Bodvarsson, and R. Bruning, Eds., pp. 1-19, Information Age Publishing, Greenwich, CT, 2005.

[38] R. Moreno and R. E. Mayer, "Interactive multimodal learning environments: special issue on interactive learning environments: contemporary issues and trends," Educational Psychology Review, vol. 19, no. 3, pp. 309-326, 2007.

[39] B. Park, J. L. Plass, and R. Brünken, "Cognitive and affective processes in multimedia learning," Learning and Instruction, vol. 29, pp. 125-127, 2014.

[40] P. R. Pintrich and E. V. de Groot, "A motivational science perspective on the role of student motivation in learning and teaching contexts," Journal of Educational Psychology, vol. 95, no. 4, pp. 667-686, 2003.

[41] M. Bannert, "Effects of reflection prompts when learning with hypermedia," Journal of Educational Computing Research, vol. 35, no. 4, pp. 359-375, 2006.

[42] S. Kalyuga, "Prior knowledge principle in multimedia learning," in The Cambridge Handbook of Multimedia Learning, E. R. Mayer, Ed., pp. 325-337, Cambridge University Press, Cambridge, Mass, USA, 2005.

[43] J. L. Plass and U. Kaplan, "Emotional design in digital media for learning," in Emotions, Technology, Design and Learning, S. Tettegah and M. Gartmeier, Eds., pp. 131-162, Elsevier, London, UK, 2016.

[44] C. E. Izard, Patterns of emotions: A New Analysis of Anxiety and Depression, Academic Press, San Diego, Calif, USA, 1972.

[45] J. J. Gross, "The emerging field of emotion regulation: an integrative review," Review of General Psychology, vol. 2, no. 3, pp. 271-299, 1998.

[46] S. E. Palmer and K. B. Schloss, "An ecological valence theory of human color preference," in Proceedings of the National Academy of Sciences of the United States of America, vol. 107, pp. 8877-8882, 2010, https://doi.org/10.1073/pnas.0906172107.

[47] A. J. Elliot and M. A. Maier, "Color and psychological functioning," Current Directions in Psychological Science, vol. 16, no. 5, pp. 250-254, 2007.

[48] A. J. Elliot, M. A. Maier, M. J. Binser, R. Friedman, and R. Pekrun, "The effect of red on avoidance behavior in achievement contexts," Personality and Social Psychology Bulletin, vol. 35, no. 3, pp. 365-375, 2009.

[49] P. N. Hamid and A. G. Newport, "Effect of colour on physical strength and mood in children," Perceptual and Motor Skills, pp. 179-185, 1989.

[50] N. J. Stone and A. J. English, “Task type, posters, and workspace color on mood, satisfaction and performance," Journal of Environmental Psychology, vol. 18, pp. 175-185, 1998. 
[51] C. Taylor, K. B. Schloss, S. E. Palmer, and A. Franklin, "Color preferences in infants and adults are different," Psychonomic Bulletin Review, vol. 20, no. 5, pp. 916-922, 2013.

[52] C. J. Boyatzis and R. Varghese, "Childrens emotional associations with colors," The Journal of Genetic Psychology, vol. 155, no. 1, Article ID 9914760, pp. 77-85, 1994.

[53] M. Hemphill, "A Note on Adults' Color-Emotion Associations," The Journal of Genetic Psychology, vol. 157, no. 3, pp. 275-280, 1996.

[54] J. Kim, J. Lee, and D. Choi, "Designing emotionally evocative homepages: an empirical study of the quantitative relations between design factors and emotional dimensions," International Journal of Human Computer Studies, vol. 6, pp. 899-940, 59.

[55] D. S. Berry and L. Z. McArthur, "Some components and consequences of a babyface," Journal of Personality and Social Psychology, vol. 48, no. 2, pp. 312-323, 1985.

[56] L. Knörzer, R. Brünken, and B. Park, "Facilitators or suppressors: effects of experimentally induced emotions on multimedia learning," Learning and Instruction, vol. 44, pp. 97-107, 2016.

[57] D. M. Dehn and S. van Mulken, "The impact of animated interface agents: a review of empirical research," International Journal of Human-Computer Studies, vol. 52, no. 1, pp. 1-22, 2000.

[58] C. Huang, "Achievement Goals and Achievement Emotions: A Meta-analysis," Educational Psychology Review, vol. 23, no. 3, pp. 359-388, 2011.

[59] D. Watson, L. A. Clark, and A. Tellegen, "Development and validation of brief measures of positive and negative affect: the PANAS scale," Journal of Personality and Social Psychology, vol. 54, no. 6, pp. 1063-1070, 1988.

[60] H. Krohne, B. Egloff, C. Kohlmann, and A. Tausch, "Untersuchungen mit einer deutschen Version der "Positive and Negative Affect Schedule"(PANAS). [Studies with a German version of the "Positive and Negative Affect Schedule" (PANAS)]," Diagnostica, vol. 42, no. 2, pp. 139-156, 1996.

[61] J. R. Crawford and J. D. Henry, "The positive and negative affect schedule (PANAS): construct validity, measurement properties and normative data in a large non-clinical sample," British Journal of Clinical Psychology, vol. 43, no. 3, pp. 245-65, 2004.

[62] C. R. B. Joyce, D. W. Zutshi, V. Hrubes, and R. M. Mason, "Comparison of fixed interval and visual analogue scales for rating chronic pain," European Journal of Clinical Pharmacology, vol. 8, no. 6, pp. 415-420, 1975.

[63] D. Watson and L. A. Clark, The PANAS-X: Manual for the Positive and Negative Affect Schedule - Expanded Form, University of Iowa, Iowa city, Iowa, USA, 1994.

[64] B. Spinath, J. Stiensmeier-Pelster, C. Schöne, and O. Dickhäuser, Scales for Assessing Motivation for Learning and Achievement, Hogrefe, Göttingen, Germany, 2002.

[65] J. Nunnally and I. Bernstein, Psychometric Theory, McGrawHill, New York, NY, USA, 3rd edition, 1994.

[66] D. G. Altmann, Practical Statistics for Medical Research, Chapman Hall/CRC Press, New York, NY, USA, 1999.

[67] D. J. Leiner, 2014. SoSci Survey. Retrieved from https://www .soscisurvey.de.

[68] J. D. Cohen, P. Cohen, S. G. West, and L. Aiken, Applied multiple regression/correlation analysis for the behavioral sciences, Lawrence Erlbaum Associates, Inc, Mahwah, NJ, USA, 3rd edition, 2003.

[69] A. Hayes, Introduction to Mediation, Moderation, and Conditional Process Analysis. A Regression-Based Approach, Guilford Press, New York, NY, USA, 2013.
[70] K. J. Preacher, P. J. Curran, and D. J. Bauer, "Computational tools for probing interactions in multiple linear regression, multilevel modeling, and latent curve analysis," Journal of Educational and Behavioral Statistics, vol. 31, no. 4, pp. 437-448, 2006.

[71] R. Pekrun, A. J. Elliot, and M. A. Maier, "Achievement goals and achievement emotions: testing a model of their joint relations with academic performance," Journal of Educational Psychology, vol. 101, no. 1, pp. 115-135, 2009.

[72] M. Ainley and J. Ainley, "Student engagement with science in early adolescence: the contribution of enjoyment to students continuing interest in learning about science," Contemporary Educational Psychology, vol. 36, no. 1, pp. 4-12, 2011.

[73] K. G. Brown, "Using computers to deliver training: which employees learn and why?" Personnel Psychology, vol. 54, no. 2, pp. 271-296, 2001.

[74] R. Custers and H. Aarts, "Positive affect as implicit motivator: on the nonconscious operation of behavioral goals," Journal of Personality and Social Psychology, vol. 89, no. 2, pp. 129-142, 2005.

[75] G. P. Latham and E. A. Locke, "Self-Regulation through Goal Setting," Organizational Behavior and Human Decision Processes, vol. 50, no. 2, pp. 212-247, 1991.

[76] D. Winters and G. P. Latham, "The effect of learning versus outcome goals on a simple versus a complex task," Group \& Organization Management, vol. 21, no. 2, pp. 236-250, 1996.

[77] K. R. Scherer, "Emotion as a multicomponent process: a model and some crosscultural," in Review of Personality and Social Psychology, P. Shaver, Ed., pp. 37-63, Sage, Beverly Hills, Calif, USA, 1984.

[78] S. D’Mello, B. Lehman, J. Sullins, R. Daigle, R. Combs, and K. Vogt, "A time for emoting: when affect-sensitivity is and isnt effective at promoting deep learning," in Proceedings of the Intelligent tutoring systems. Proceedings of 10th interanational conference on intelligent tutoring systems, V. Aleven, J. Kay, and J. Mostow, Eds., pp. 245-254, 2010. 


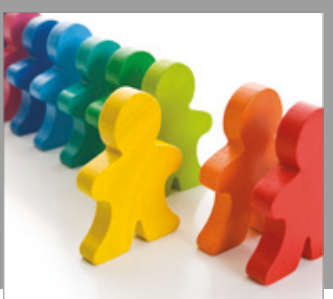

Autism

Research and Treatment
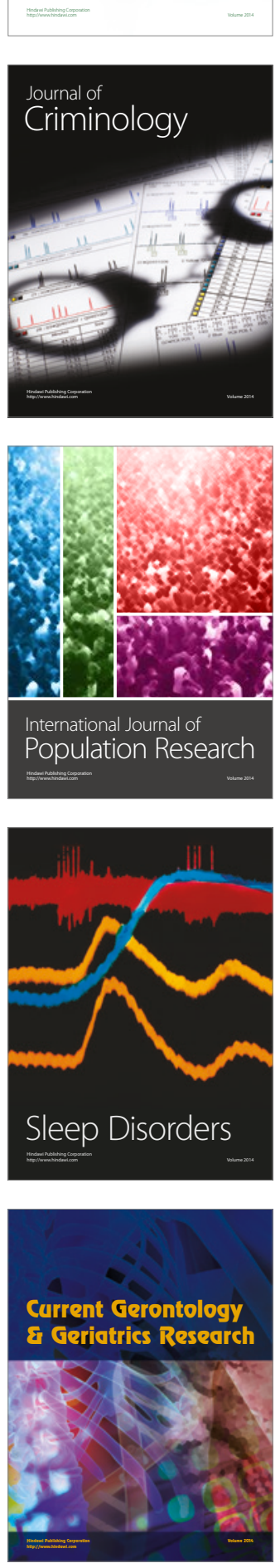

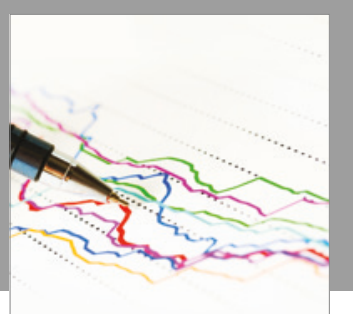

Economics

Research International

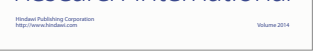

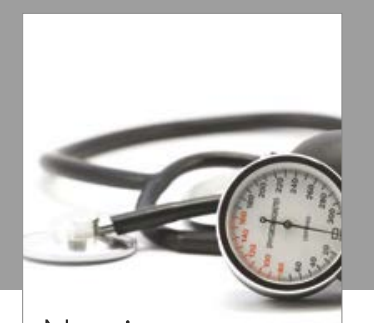

Nursing

Research and Practice

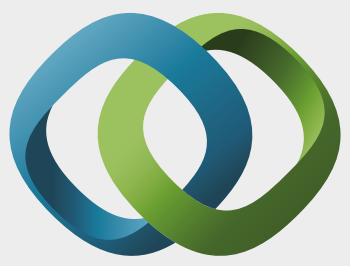

\section{Hindawi}

Submit your manuscripts at

https://www.hindawi.com
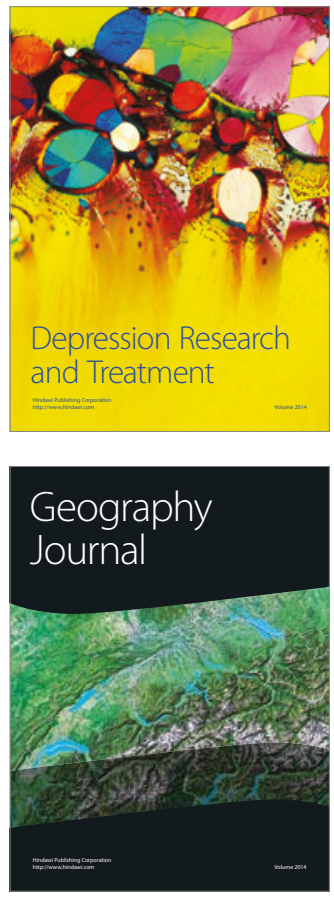
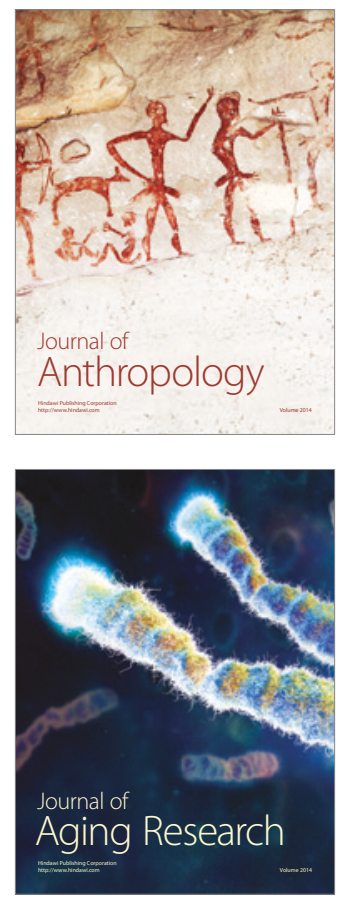
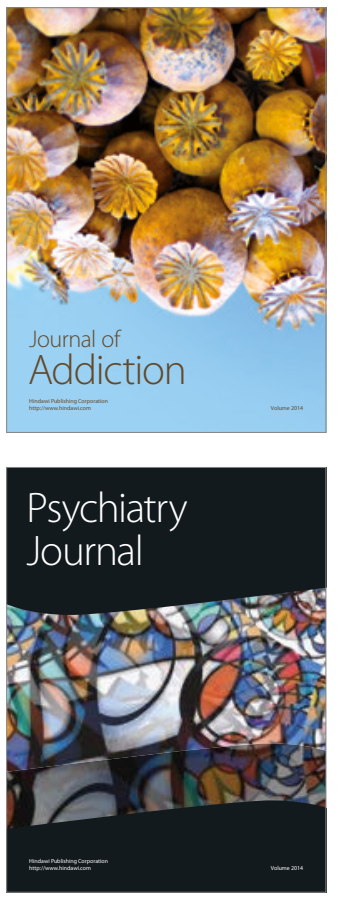

Child Development

Research

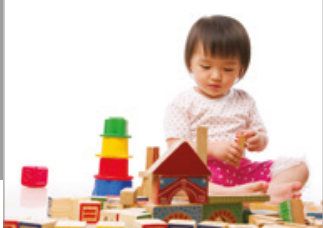

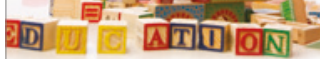
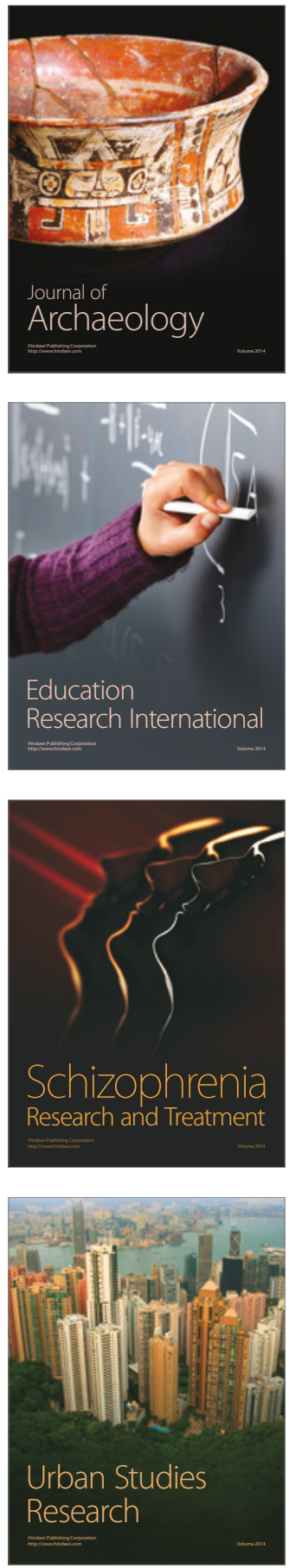